
(по результатам аутопсийных исследований)

\author{
Федоров Д.Н.' • Коростелева П.А.' • Зыбин Д.И.' • Попов М.А.' • Тюрина В.М.. • Варламов А.В. ${ }^{1}$
}

Обоснование. Изучение патогенеза и морфогенеза новой коронавирусной инфекции COVID-19 в настоящее время представляет собой актуальный вопрос, требующий накопления фактических данных, их обработки и анализа. Понимание механизмов развития заболевания и их особенностей позволит улучшить качество диагностики и эффективность лечения, а также снизить летальность. Цель - изучить морфологические и иммуногистохимические особенности изменений ткани лимфатических узлов бронхолегочной группы у пациентов c COVID-19 на материале аутопсийных исследований. Материал и методы. Исследование выполнено на 44 аутопсийных наблюдениях пациентов, находившихся на лечении и умерших от новой коронавирусной инфекции COVID-19 в ГБУЗ МО МОНИКИ им. М.Ф. Владимирского. Использовались макроскопический, гистологический и иммуногистохимический методы исследования. Результаты. Были обнаружены стереотипные изменения в морфологии и клеточном составе лимфоидной ткани, зависящие от длительности течения заболевания. Выявлены признаки угнетения В-клеточного звена иммунитета, что проявляется уменьшением количества и размеров лимфоидных фолликулов и определяется не позже чем на 7-е сутки от начала заболевания. У пациентов с длительностью заболевания до 14 суток Т-клеточный состав лимфатического узла представлен преимущественно $\mathrm{CD}^{+}$Т-лимфоцитами. С увеличением длительности заболевания отмечается постепенный рост числа лимфоидных фолликулов и их размеров, изменяется соотношение $\mathrm{CD}^{+}$Т-лимфоцитов и CD8 ${ }^{+}$Т-лимфоцитов в сторону повышения количества последних, после 21-х суток от начала заболевания соотношение выравнивается. Заключение. Полученные результаты свидетельствуют о прямом повреждающем действии вируса SARS-CoV-2 на ткань лимфатических узлов бронхолегочной группы.
Обсуждается возможность развития вторичного транзиторного иммунодефицита и инфекционных осложнений у пациентов, перенесших новую коронавирусную инфекцию.

Ключевые слова: инфекция COVID-19, патогенез, патологическая анатомия, лимфоидная ткань

Для цитирования: Федоров ДН, Коростелева ПА, Зыбин ДИ, Попов МА, Тюрина ВМ, Варламов АВ. Морфологическая и иммуногистохимическая характеристика изменений в лимфатических узлах бронхолегочной группы у пациентов с новой коронавирусной инфекцией COVID-19 (по результатам аутопсийных исследований). Альманах клинической медицины. 2020;48(S1):S37-42. do:: 10.18786/2072-0505-2020-48-034.

Поступила 23.07.2020; доработана 28.08.2020; принята к публикации 31.08.2020; опубликована онлайн 04.09.2020

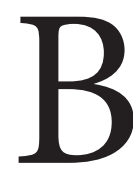
озбудителем новой коронавирусной инфекции COVID-19 стал одноцепочечный PHK-вирус SARS-CoV-2, который принадлежит к семейству Coronaviridae и отнесен ко II группе патогенности $[1,2]$.

Проникновение в организм человека происходит через клетки-мишени, имеющие рецепторы ангиотензинпревращающего фермента II типа (АПФ2) и мембранный белок CD147 [3, 4], наиболее часто - через эпителий воздухоносных путей и альвеолоциты легких, слизистую оболочку желудочно-кишечного тракта. Поражение, обусловленное вирусом SARS-CoV-2, обычно носит системный характер, что связано с широкой экспрессией рецепторов АПФ2 и CD147 на поверхности клеток различных органов, в том числе на эндотелии кровеносных сосудов, нефротелии, в миокарде и на клетках центральной нервной системы [5]. К основным звеньям патогенеза органных поражений при COVID-19, кроме непосредственного повреждающего действия вируса на клетки-мишени, можно отнести нарушения 
со стороны системы свертывания крови, связанные с дисфункцией эндотелия и проявляющиеся развитием тромбозов и геморрагий, и избыточный, нерегулируемый выброс провоспалительных цитокинов («цитокиновый шторм»). Следует отметить, что все звенья патогенеза COVID-19 неразрывно связаны между собой и формируют порочный круг, взаимно усугубляя повреждающее действие друг друга и обусловливая системный характер повреждений и их вариативность [6]. В части клинических наблюдений отмечено развитие лимфопении, преимущественно у пациентов с тяжелой формой COVID-19 [7], что может быть связано как с прямым цитопатическим действием вируса на лимфоидную ткань, так и с нерегулируемым выбросом провоспалительных цитокинов. Однако достоверная информация о возможности репликации вируса SARS-CoV-2 в лимфоцитах отсутствует.

При аутопсии патологические изменения выявляются преимущественно в органах дыхательной системы (легкие, трахея, бронхи). Частыми находками также становятся поражения почек, миокарда и органов иммунной системы - лимфатических узлов и селезенки.

Цель нашего исследования - описание и оценка морфологических и иммуногистохимических изменений в ткани лимфатических узлов бронхолегочной группы при аутопсии умерших с диагнозом «новая коронавирусная инфекция COVID-19».

\section{Материал и методы}

В исследование включены данные 44 аутопсий пациентов, умерших в инфекционном отделении ГБУЗ МО МОНИКИ им. М.Ф. Владимирского от новой коронавирусной инфекции COVID-19, подтвержденной результатом теста, проведенного методом полимеразной цепной реакции, а также пациентов с отрицательным или неопределенным результатом, но с существенными клиническими подозрениями на инфекцию COVID-19 (одышка, повышение температуры, мышечная слабость, симптомы желудочно-кишечного расстройства, дисгевзия, аносмия) и подтвержденной картиной вирусной пневмонии по данным компьютерной томографии. Для исследования были отобраны случаи летальных исходов без сочетанной гематологической патологии.

У всех пациентов в ходе развития клинической картины заболевания в течение приблизительно 7-10 дней наблюдалась клиника COVID-19 с последующим быстрым развитием декомпенсации функции дыхательной системы. На Федоров Дмитрий
Николаевич канд. мед. наук, доцент, заведующий патологоанатомическим отделением'; ORCID: https://orcid.org/00000001-6697-122X $\triangle 129110$, г. Москва, ул. Щепкина, 61/2-13, Российская Федерация. Тел.: +7 (903) 6620910. E-mail: mmapath_dnf @mail.ru

\section{Коростелева Полина} Артуровна - врачпатологоанатом, патологоанатомическое отделение'; ORCID: https://orcid.org/00000001-7867-5241

\section{Зыбин Дмитрий}

Игоревич - канд. мед. наук, руководитель отделения

кардиохирургии'; ORCID: https://orcid.org/00000001-7087-5441

\section{Попов Михаил} Александрович врач-кардиохирург, науч. сотр. отделения кардиохирургии для взрослых'; ORCID: https:// orcid.org/0000-00020316-8410

\section{Тюрина Влада} Михайловна клинический ординатор, патологоанатомическое отделение'; ORCID: https://orcid.org/00000002-1426-0917

\section{Варламов Андрей} Владимирович врач-патологоанатом, патологоанатомическое отделение'; ORCID: https://orcid.org/00000002-9866-9567

1 ГБУз МО «Московский областной научно-исследовательский клинический институт им. М.Ф. Владимирского»; 129110, г. Москва, ул. Щепкина, 61/2, Российская Федерация компьютерных томограммах отмечались затемнения по типу «матового стекла», соответствующие острому респираторному дистресс-синдрому. Средние значения показателей пациентов представлены в таблице.

Медикаментозная терапия проводилась в соответствии с временными методическими рекомендациями по COVID-19 Министерства здравоохранения Российской Федерации.

Аутопсии выполнялись, как правило, в течение 24 часов после констатации биологической смерти пациента. Аутопсийный материал, подлежащий исследованию, фиксировали в $10 \%$ нейтральном (забуференном) формалине в течение 10-24 часов. После вырезки фрагменты ткани обрабатывались в гистопроцессоре Leica TP1020 (Leica Biosystems, Германия) по стандартному протоколу, после чего производилась заливка в парафиновые блоки. Гистологические срезы толщиной 3-5 мкм получали при помощи микротома Leica RM2245 (Leica Biosystems, Германия). Изготовленные гистологические препараты окрашивали гематоксилином и эозином в гистостейнере Leica Autosteiner XL (Leica Biosystems, Германия). В части случаев (лимфатические узлы и селезенка) выполнялось иммуногистохимическое исследование с использованием иммуностейнера Leica Bond-MAX (Leica Biosystems, Германия).

Иммуногистохимическое исследование проводилось с маркером субпопуляции Т-лимфоцитов хелперов/супрессоров CD4 (RTU, клон 4B12, Leica Biosystems, Германия), маркером субпопуляции Т-лимфоцитов киллеров/супрессоров и NKклеток CD8 (RTU, клон 4B11, Leica Biosystems, Германия), маркером гистиоцитов и макрофагов CD15 (RTU, клон carb-3, DAKO, Дания), маркером субпопуляции В-лимфоцитов CD20 (RTU, клон MJ1, Leica Biosystems, Германия) и маркером моноцитов, макрофагов и гистиоцитов CD68 (RTU, клон 514H12, Leica Biosystems, Германия).

Данные исследования выполнялись в соответствии с протоколами, рекомендованными производителями первичных антител и иммуностейнера. Экспрессия указанных маркеров оценивалась полуколичественным методом по стандартной методике.

Статистическую обработку данных проводили в программах Statistica 13.2 (Dell inc., США) и Microsoft Excel 2016 (Microsoft corp., США). Для количественных переменных рассчитывали среднее арифметическое значение и стандартное отклонение $(\mathrm{M} \pm \mathrm{SD})$.

Этическая экспертиза не выполнялась. 


\section{Результаты и обсуждение}

Все наблюдения (44 аутопсии) были распределены по срокам длительности заболевания на 3 группы: 7-14 дней (29 наблюдений), 15-21 день (12 наблюдений) и более 21 дня (3 наблюдения).

Макроскопически лимфатические узлы бронхолегочной группы, вне зависимости от продолжительности заболевания, были увеличены в размерах, на разрезе серо-розового цвета, с явлениями полнокровия.

У пациентов 1-й группы при гистологическом исследовании были выявлены следующие особенности строения лимфатических узлов бронхолегочной группы: рисунок стерт, лимфоидные фолликулы и светлые герминативные центры не визуализируются, в синусах определяются скопления крупных клеток с морфологией моноцитов (рис. 1). При иммуногистохимическом исследовании были обнаружены лимфоидные фолликулы небольшого размера, представленные $\mathrm{CD} 20^{+} \mathrm{B}$-лимфоцитами (в части лимфатических узлов наблюдались только в подкапсульных отделах); скопления крупных клеток в синусах, представленные $\mathrm{CD}_{68}^{+}$и $\mathrm{CD} 15^{+}$моноцитами; Т-клеточный состав лимфатического узла был представлен преимущественно $\mathrm{CD} 4^{+} \mathrm{T}$-лимфоцитами, соотношение $\mathrm{CD}^{+}{ }^{+}$и $\mathrm{CD} 8^{+}$Т-лимфоцитов составило 4:1 (рис. 2).

У пациентов 2-й группы при гистологическом исследовании были выявлены следующие особенности строения лимфатических узлов: рисунок стерт, определяются немногочисленные мелкие лимфоидные фолликулы, светлые герминативные центры в них не визуализируются, в синусах и коре - обширные многочисленные скопления крупных клеток с морфологией моноцитов (рис. 3). При иммуногистохимическом исследовании были
Основные клинические данные пациентов

\begin{tabular}{|c|c|}
\hline Показатель & Значение \\
\hline Общее число наблюдений & 44 \\
\hline 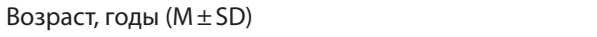 & $55,4 \pm 9,6$ \\
\hline \multicolumn{2}{|l|}{ Пол, n (\%) } \\
\hline женский & $20(45,5)$ \\
\hline мужской & $24(54,5)$ \\
\hline $\begin{array}{l}\text { COVID-19, вирусологически подтвержденный } \\
\text { ПЦР-исследованием, n (\%) }\end{array}$ & $34(77,2)$ \\
\hline Средняя длительность заболевания, дни & 13 \\
\hline Средняя продолжительность ИВЛ, дни & 7,4 \\
\hline Средняя степень тяжести пневмонии по данным КТ & 3,3 \\
\hline
\end{tabular}

ИВЛ - искусственная вентиляция легких, КТ - компьютерная томография, ПЦР - полимеразная цепная реакция

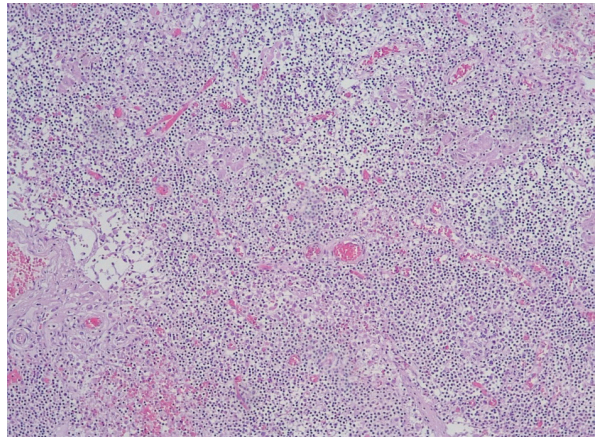

Рис. 1. Гистологическое исследование: рисунок строения лимфатического узла стерт, лимфоидные фолликулы и герминативные центры не визуализируются, определяются небольшие скопления клеток с морфологией моноцитов (окраска гематоксилин-эозином; × 100)
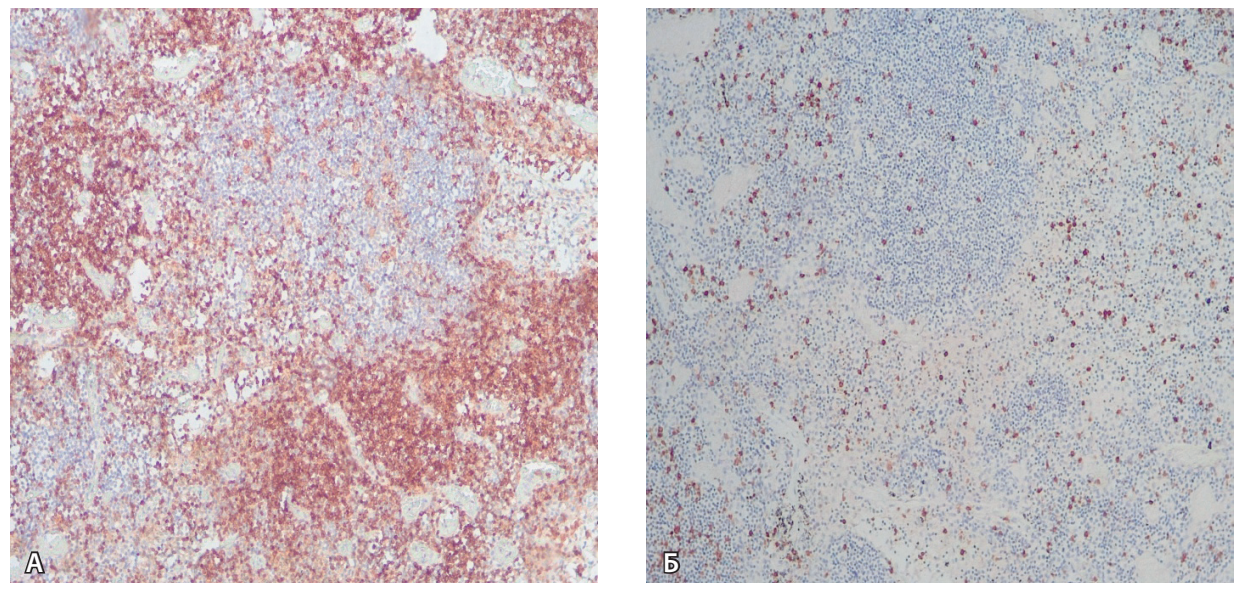

Рис. 2. Иммуногистохимическое исследование лимфатического узла (× 100): A - CD4+, Б - CD8+; соотношение $\mathrm{CD}^{+}$и $\mathrm{CD}^{+}$Т-лимфоцитов составляет 4:1 


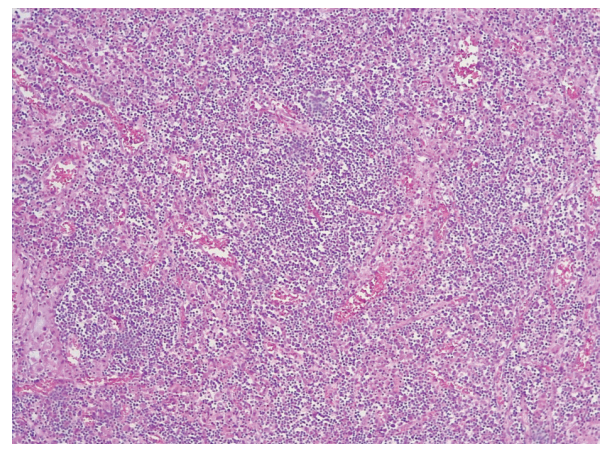

Рис. 3. Гистологическое исследование: рисунок строения лимфатического узла стерт, определяются немногочисленные мелкие лимфоидные фолликулы без герминативных центров, обширные скопления крупных клеток с морфологией моноцитов (окраска гематоксилин-эозином; $\times 100)$

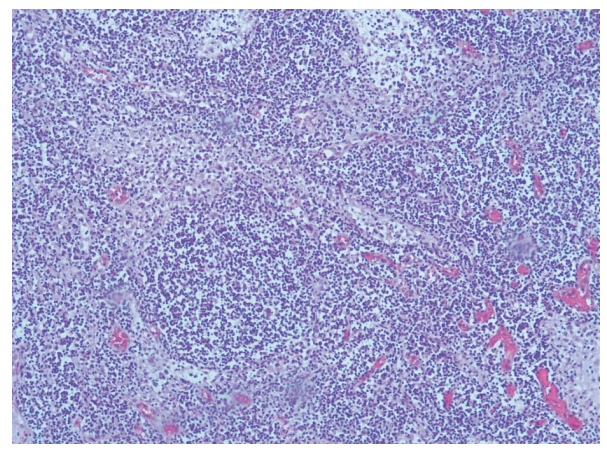

Рис. 5. Гистологическое исследование: рисунок строения лимфатического узла частично стерт, определяются лимфоидные фолликулы небольшого размера без герминативных центров и небольшие скопления клеток с морфологией моноцитов (окраска гематоксилин-эозином;×100)
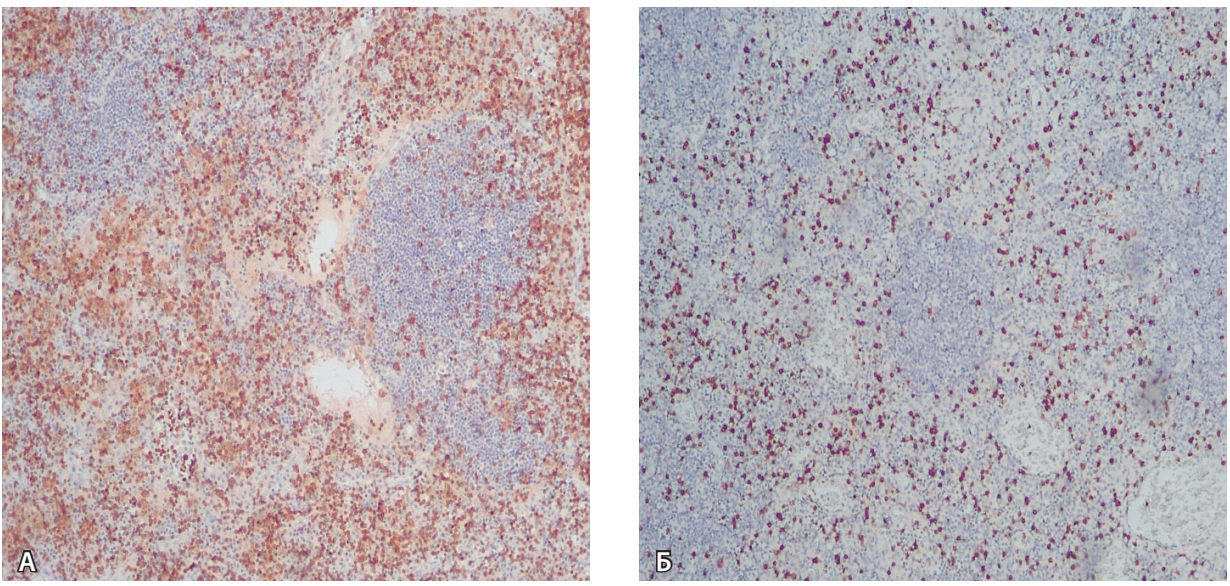

Рис. 4. Иммуногистохимическое исследование лимфатического узла (× 100): A - CD4+, Б - CD8+; соотношение $\mathrm{CD}^{+}$и $\mathrm{CD}^{+}{ }^{+}$Т-лимфоцитов составляет 5:3
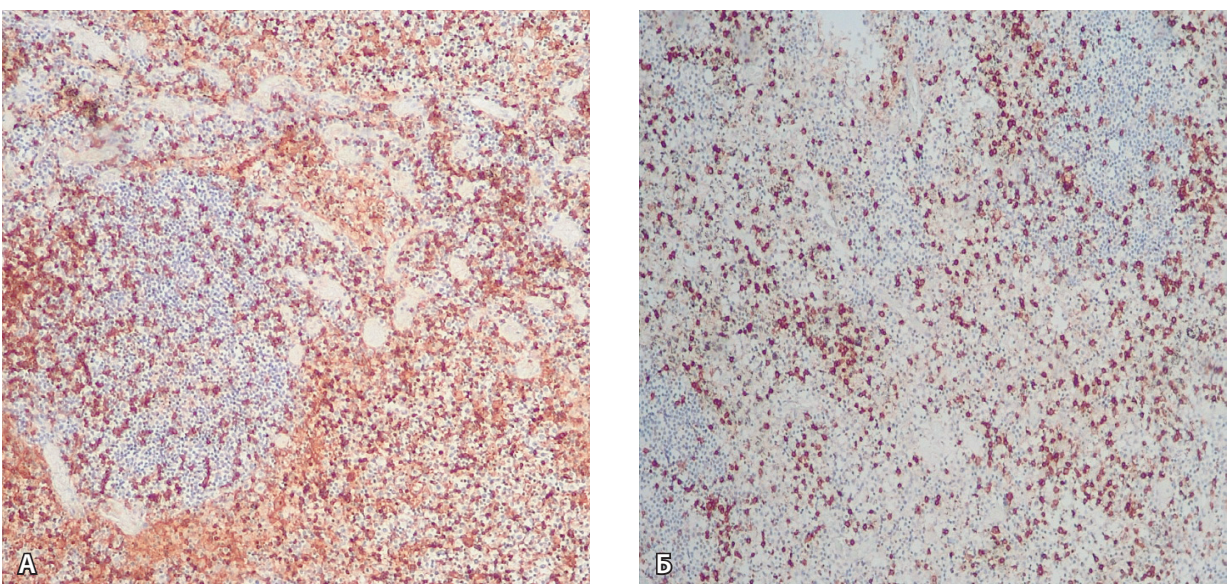

Рис. 6. Иммуногистохимическое исследование лимфатического узла (× 100): A - CD4+, Б - CD8+; соотношение $\mathrm{CD}^{+}$и $\mathrm{CD} 8^{+}$Т-лимфоцитов составляет 1:1

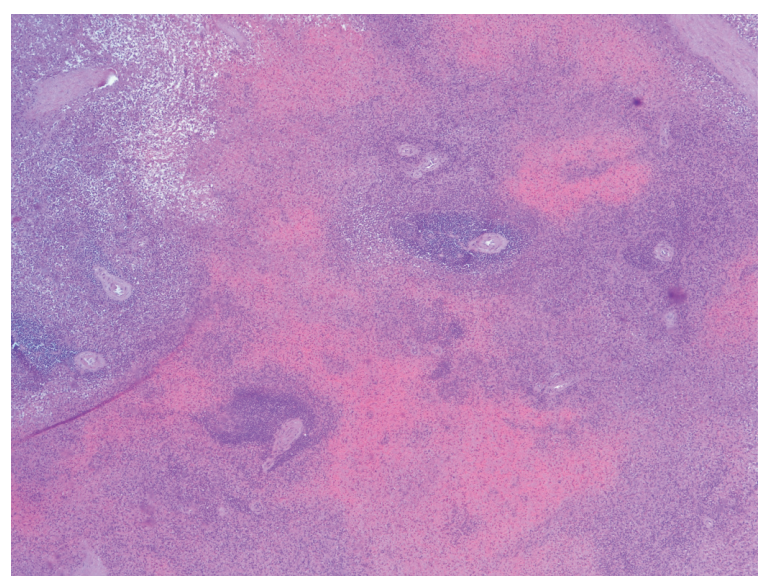

Рис. 7. Морфологическое исследование селезенки: выраженное полнокровие красной пульпы, истощение лимфоидной ткани (окраска гематоксилин-эозином;×40) обнаружены лимфоидные фолликулы преимущественно среднего размера, представленные $\mathrm{CD} 20^{+}$ B-лимфоцитами; скопления крупных клеток в синусах, представленные $\mathrm{CD}_{68}^{+}$и $\mathrm{CD} 15^{+}$моноцитами; в Т-клеточном составе лимфатического узла незначительно преобладали $\mathrm{CD} 4^{+}$Т-лимфоциты, соотношение $\mathrm{CD}^{+}$и $\mathrm{CD} 8^{+}$Т-лимфоцитов составило в среднем 1:1 (рис. 6).

При морфологическом исследовании ткани селезенки во всех 44 наблюдениях вне зависимости от длительности течения заболевания наблюдались стереотипные изменения: полнокровие красной пульпы, лимфоидные фолликулы белой пульпы резко уменьшены в размерах и представлены небольшим количеством лимфоидных элементов, сосуды полнокровны, с явлениями стаза и сладжа эритроцитов, формированием 
микротромбов, в отдельных случаях встречались фокусы мелких инфарктов (рис. 7).

На основании полученных результатов можно сделать вывод, что вирус SARS-CoV-2, вероятно, оказывает прямое цитопатическое воздействие на ткань лимфатических узлов бронхолегочной группы, вызывая угнетение В-клеточного звена иммунитета, что проявляется уменьшением количества и размеров лимфоидных фолликулов и определяется не позже чем на 7-е сутки от начала заболевания. Следует отметить, что подобные изменения в ткани лимфатических узлов наблюдаются и при некоторых других вирусных инфекциях, передающихся воздушно-капельным путем, например, при кори $[8,9]$. С увеличением длительности заболевания отмечается постепенный рост числа лимфоидных фолликулов и их размеров, изменяется соотношение $\mathrm{CD} 4^{+}$и $\mathrm{CD} 8^{+}$ Т-лимфоцитов в сторону повышения количества последних, в то время как количество $\mathrm{CD} 4^{+}$ Т-лимфоцитов остается неизменным.

\section{Заключение}

Выполненное морфологическое и иммуногистохимическое исследование продемонстрировало,

\section{Дополнительная информация}

\section{Финансирование}

Работа проведена без привлечения дополнительного финансирования со стороны третьих лиц.

\section{Конфликт интересов}

Авторы декларируют отсутствие явных и потенциальных конфликтов интересов, связанных с публикацией настоящей статьи.

Участие авторов

Д.Н. Федоров - концепция и дизайн исследования, сбор и обработка материала, анализ полученных данных, подготовка иллюстративного материала и написание текста статьи, координация взаимодействия что при поражении вирусом SARS-CoV-2 происходит угнетение В-клеточного звена иммунитета, при этом Т-клеточное звено характеризуется изменением соотношения $\mathrm{CD} 4^{+} / \mathrm{CD}^{+}$клеток, зависящим от длительности заболевания. На основании полученных данных можно предположить, что у пациентов, перенесших новую коронавирусную инфекцию COVID-19, развивается вторичный транзиторный иммунодефицит, обусловленный воздействием вируса на ткань лимфатических узлов, что в дальнейшем может приводить к возникновению тяжелых поздних осложнений, вызванных бактериальной и иной патогенной флорой. Таким образом, пациенты с тяжелым течением COVID-19 могут входить в группу риска по развитию бронхолегочных осложнений, обусловленных как вторичным иммунодефицитом, так и непосредственным поражением легочной ткани в процессе развития инфекционного процесса. Высокая вероятность формирования вторичных хронических обструктивных и рестриктивных изменений легких требует соответствующего наблюдения и лечения после перенесенной коронавирусной инфекции. (\$)

\section{Литература / References}

1. Министерство здравоохранения Российской Федерации. Временные методические рекомендации: профилактика, диагностика и лечение новой коронавирусной инфекции (COVID-19) [Интернет]. Версия 7 (03.06.2020). М.; 2020. 166 с. Доступно на: https://static-0.rosminzdrav.ru/system/ attachments/attaches/000/050/584/original/03062020_\%D0\%9CR_COVID-19_v7.pdf. [Ministry of Health of Russian Federation. Temporary methodological recommendations: prevention, diagnostics and treatment of new coronavirus infection (COVID-19) [Internet]. v. 7 (2020 Jun 3). Moscow; 2020. 166 p. Russian. Available from: https://static-0.rosminzdrav.ru/ system/attachments/attaches/000/050/584/
original/03062020_\%D0\%9CR_COVID-19_ v7.pdf.]

2. Park WB, Kwon NJ, Choi SJ, Kang CK, Choe PG, Kim JY, Yun J, Lee GW, Seong MW, Kim NJ, Seo JS, Oh MD. Virus Isolation from the First Patient with SARS-CoV-2 in Korea. J Korean Med Sci. 2020;35(7):e84. doi: 10.3346/jkms.2020.35. e84.

3. Hoffmann M, Kleine-Weber $\mathrm{H}$, Schroeder $\mathrm{S}$, Krüger N, Herrler T, Erichsen S, Schiergens TS, Herrler G, Wu NH, Nitsche A, Müller MA, Drosten C, Pöhlmann S. SARS-CoV-2 Cell Entry Depends on ACE2 and TMPRSS2 and Is Blocked by a Clinically Proven Protease Inhibitor. Cell. 2020;181(2):271-80.e8. doi: 10.1016/j. cell.2020.02.052.
4. Wang K, Chen W, Zhou YS, Lian JQ, Zhang Z, Du P, Gong L, Zhang Y, Cui HY, Geng JJ, Wang B, Sun $X X$, Wang $C F$, Yang $X$, Lin $P$, Deng $Y Q$, Wei $D$, Yang $X M$, Zhu YM, Zhang $K$, Zheng $Z H$, Miao JL, Guo T, Shi Y, Zhang J, Fu L, Wang QY, Bian H, Zhu P, Chen ZN. SARS-CoV-2 invades host cells via a novel route: CD147-spike protein [Internet]. bioRxiv. 2020 Mar 14. doi: 10.1101/2020.03.14.988345.

5. Walls AC, Park YJ, Tortorici MA, Wall A, MCGuire AT, Veesler D. Structure, Function, and Antigenicity of the SARS-CoV-2 Spike Glycoprotein. Cell. 2020;181(2):281-92.e6. doi: 10.1016/j.cell.2020.02.058.

6. Perrella A, Trama U, Bernardi FF, Russo G, Monastra L, Fragranza F, Orlando V, Co- 
scioni E. Editorial - COVID-19, more than a viral pneumonia. Eur Rev Med Pharmacol Sci. 2020;24(9):5183-5. doi: 10.26355/eurrev_202005_21216.

7. Lin L, Lu L, Cao W, Li T. Hypothesis for potential pathogenesis of SARS-CoV-2 infection - a review of immune changes in patients with viral pneumonia. Emerg Microbes Infect. 2020;9(1):727-32. doi: $10.1080 / 22221751.2020 .1746199$.

8. Mason WH. Measles (Chapter 246). In: Kliegman RM, Stanton BMD, St. Geme J, Schor NF, eds. Nelson Textbook of Pediatrics. $20^{\text {th }}$ ed. Elsevier; 2016. p. 1542-8.e1.
9. Gershon AA. Measles Virus (Chapter 160). In: Mandell G, Bennett J, Dolin R. Mandell, Douglas and Bennett's Principles and Practice of Infectious Diseases. $7^{\text {th }}$ ed. Churchill Livingstone; 2009. p. 2229-36.e2.

\title{
Morphological and immunohistochemical characteristics of changes in the bronchopulmonary lymph nodes in patients with a new COVID-19 coronavirus infection (based on autopsy results)
}

\author{
D.N. Fedorov' • P.A. Korosteleva' • D.I. Zybin • M.A. Popov • \\ V.M. Tyurina ${ }^{1} \cdot$ A.V. Varlamov ${ }^{1}$
}

Background: Research into the pathogenesis and morphogenesis of new coronavirus infection (COVID-19) is currently a hot topic that requires the accumulation, management and analysis of the data. Understanding the mechanisms of the disease and their characteristics would help to improve diagnostic quality, treatment efficacy and reduce mortality. Aim: To identify morphological and immunohistochemical characteristics of the bronchopulmonary lymph node tissues in autopsied patients with COVID-19. Materials and methods: The study was carried out on 44 autopsy samples from patients who were hospitalized and died from the new coronavirus infection COVID-19 in the Moscow Regional Research and Clinical Institute. Macroscopic, histological, and immunohistochemical assessment methods were used. Results: We found stereotypical abnormalities in the morphology and cellular composition of the lymphoid tissue depending on the duration of the disease. These included signs of B-cell-mediated immunity suppression manifested by a decrease in the number and size of lymphoid follicles and occurs at latest after 7 days from the onset of the disease. In the patients with the disease duration of up to 14 days, the T-cell pool of the lymph nodes is represented mainly by $\mathrm{CD}_{4}{ }^{+} \mathrm{T}$-lymphocytes. With longer duration of the disease, there is a gradual increase in the number of lymphoid follicles and their sizes, with changes of the $\mathrm{CD} 4^{+}$to $\mathrm{CD} 8^{+} \mathrm{T}$-cell ratio towards higher $\mathrm{CD} 8^{+}$counts. After 21 days of the disease, the $\mathrm{CD} 4^{+}$to $\mathrm{CD} 8^{+}$ratio levels off. Conclusion: The results obtained indicate a direct damaging effect of SARS-CoV-2 on the lymph node tissues of the bronchopulmonary group. The possibility of secondary transient immune deficiency and infectious complications in patients with a new coronavirus infection is discussed.

Key words: COVID-19 infection, pathogenesis, pathological anatomy, lymphoid tissue

For citation: Fedorov DN, Korosteleva PA, Zybin DI, Popov MA, Tyurina VM, Varlamov AV. Morphological and immunohistochemical characteristics of changes in the bronchopulmonary lymph nodes in patients with a new COVID-19 coronavirus infection (based on autopsy results). Almanac of Clinical Medicine. 2020;48(S1):S37-42. doi: 10.18786/2072-0505-202048-034.

Received 23 July 2020; revised 28 August 2020; accepted 31 August 2020; published online 4 September 2020

\section{Conflict of interests}

The authors declare no obvious and potential conflicts of interests related to the publication.

\section{Authors' contributions}

D.N. Fedorov, the study concept and design, data collection and analysis, preparation of the illustrations, text writing coordination between the authors; P.A. Korosteleva, study concept and design, data collection and analysis, analysis and interpretation of the study results, preparation of the illustrations, text writing; D.I. Zybin, design of clinical part of the study, analysis and interpretation of the study results, text writing and editing; M.A. Popov, design of clinical part of the study, analysis and interpretation of the study results, text writing and editing; V.M. Tyurina, literature analysis, data collection and analysis, methodology; A.V. Varlamov, study concept and design, data collection and analysis, text editing. All the authors have made their significant contributions to the research and preparation of the article, have read and approved the final version before publication. 